\title{
Acute Neuronal Apoptosis in a Rat Model of Multiple Sclerosis
}

\author{
Roman Meyer, ${ }^{2}$ Robert Weissert, ${ }^{2}$ Ricarda Diem, ${ }^{1}$ Maria K. Storch, ${ }^{3}$ Katrien L. de Graaf, ${ }^{2}$ Birgit Kramer, ${ }^{1}$ and \\ Mathias Bähr ${ }^{1}$
}

${ }^{1}$ Neurologische Universitätsklinik, 37075 Göttingen, Germany, 2Neurologische Universitätsklinik, 72076 Tübingen, Germany, and ${ }^{3}$ Neurologische Universitätsklinik, 8036 Graz, Austria

Demyelination caused by inflammation of the CNS has been considered to be a major hallmark of multiple sclerosis (MS). Using experimental autoimmune encephalomyelitis, a model of MS, we demonstrate that an immune-mediated attack of the optic nerve is accompanied by an early degeneration of retinal ganglion cells (RGCs). The decrease of neuronal cell density was correlated with functional disabilities as assessed by visual evoked cortical potentials and electroretinogram. Visual acuity was significantly reduced. DNA degradation and activation of caspase-3 in RGCs indicate that cell death of RGCs is apoptotic. These findings show for the first time that an inflammatory attack against myelin components can lead to acute neuronal cell loss by apoptosis.

Key words: experimental autoimmune encephalomyelitis; visual evoked potentials; electroretinogram; CNS pathology; caspase-3; retinal ganglion cells
Multiple sclerosis (MS) is an inflammatory and demyelinating disease of the CNS with relapsing-remitting or chronic disease course (Noseworthy et al., 2000). Combined autoimmune attack by $\mathrm{T}$ - and B-cells against myelin sheaths formed by oligodendrocytes leads to focal lesions in the CNS (Brosnan et al., 1996; Lassmann et al., 1998). Until recently, research and clinical interventions were mainly focused on the modulation or suppression of the myelin-protein-sheath-directed immune attack of the disease. However, during the last years, it has become increasingly apparent that the long-term disability in MS correlates better with axonal loss compared with acute inflammatory lesions and the degree of demyelination (Trapp et al., 1998, 1999; Coles et al., 1999; Noseworthy et al., 2000).

Experimental autoimmune encephalomyelitis (EAE) is the principal model of MS (Wekerle et al., 1994). Only recently, rat models mimicking many aspects of MS could be established (Storch et al., 1998; Weissert et al., 1998; Kornek et al., 2000). Active immunization of female brown Norway $(\mathrm{BN})$ rats with the extracellular domain of recombinant rat myelin oligodendrocyte glycoprotein 1-125 (rrMOG ${ }^{\text {Igd }}$ ) in complete Freund's adjuvant (CFA) leads to optic neuritis or neuromyelitis optica (Storch et al., 1998; Weissert et al., 1998; Stefferl et al., 1999).

In the present study, we used MOG-EAE in BN rats not only to examine the optic nerve itself as a direct target of the immune attack but also to study the survival of retinal ganglion cells (RGCs), the neurons that form the axons of the optic nerve. This is of major importance, because up to now, mechanisms that lead to inflammation-induced cell death in MS and EAE have not been defined sufficiently in vivo. We used electrophysiological and

Received March 8, 2001; revised May 31, 2001; accepted June 5, 2001.

This work was supported by the Deutsche Forschungsgemeinschaft (DFG We 1947/2-1, SFB 510 Project D6, and Ba 949/12-1/-2). We thank Philipp Grötsch for fruitful discussions and helpful comments on this manuscript. We also thank Heike Pfrommer and Susanne Thomsen for expert technical assistance.

Correspondence should be addressed to Ricarda Diem, Neurologische Universitätsklinik, Robert-Koch-Strasse 40, Station 3012, D-37075 Göttingen, Germany. E-mail: ricardadiem@t-online.de.

R. Meyer's present address: Profos GmbH, 93040 Regensburg, Germany.

Copyright (C) 2001 Society for Neuroscience $0270-6474 / 01 / 216214-07 \$ 15.00 / 0$ histological techniques to determine functional and morphological aspects of RGC pathology.

\section{MATERIALS AND METHODS}

Rats. Female BN rats $8-10$ weeks of age were used in all experiments. They were obtained from Charles River Wiga (Sulzfeld, Germany) and kept under environmentally controlled conditions without the presence of pathogens. All experiments that involve animal use were performed in compliance with the relevant laws and institutional guidelines. These experiments have been approved by the local authorities of Tübingen, Germany.

Immunogen. $\mathrm{rrMOG}^{\mathrm{Igd}}$, corresponding to the $\mathrm{N}$-terminal sequence of rat MOG (amino acids 1-125), was expressed in Escherichia coli and purified to homogeneity by chelate chromatography (Weissert et al., 1998). The purified protein in $6 \mathrm{M}$ urea was dialyzed then against PBS to obtain a preparation that was stored at $-20^{\circ} \mathrm{C}$.

Induction and evaluation of EAE. The rats were anesthetized by inhalation anesthesia with methoxyflurane (Metofane; Pitman-Moore, Mundelein, IL) and injected intradermally at the base of the tail with a total volume of $100 \mu \mathrm{l}$ of inoculum, containing $50 \mu \mathrm{g}$ of $\mathrm{rrMOG}^{\mathrm{Igd}}$ in saline emulsified (1:1) with CFA (Sigma, St. Louis, MO) containing 200 $\mu \mathrm{g}$ of heat-inactivated mycobacterium tuberculosis (strain H 37 RA; Difco Laboratories, Detroit, MI). Rats were scored for clinical signs of EAE and weighed daily. The signs were scored as follows: grade 1, tail weakness or tail paralysis; grade 2, hindleg paraparesis or hemiparesis; grade 3 , hindleg paralysis or hemiparalysis; grade 4, complete paralysis (tetraplegy), moribund state, or death (data not shown).

The general time course of the experiment was as follows: electrophysiological measurements were performed $14-30 \mathrm{~d}$ after immunization and 48-72 hr after the onset of clinical symptoms. Immediately after the end of the recording, animals received an overdose of chloral hydrate. Retinas were removed for RGC counting and immunohistochemistry. Optic nerves together with brains and spinal cords were taken for histological evaluation.

Retrograde labeling of RGCs. Two weeks before immunization was done, adult $\mathrm{BN}$ rats were anesthetized with intraperitoneal chloral hydrate $(0.42 \mathrm{mg} / \mathrm{kg}$ body weight), the skin was incised mediosagitally, and holes were drilled into the skull above each superior colliculus $(6.8 \mathrm{~mm}$ dorsal and $2 \mathrm{~mm}$ lateral from bregma). We injected stereotactically $2 \mu \mathrm{l}$ of the fluorescent dye Fluorogold (FG; 5\% in normal saline) (Fluorochrome Inc., Englewood, CO) into both superior colliculi.

Electrophysiological recordings. The rats were anesthetized by intraperitoneal injection of $20 \%$ urethane $(6 \mathrm{ml} / \mathrm{kg}$ body weight $)$ and mounted on a stereotaxic device. During the experiment, body temperature was maintained between 35 and $37^{\circ} \mathrm{C}$ with a heating pad, and the electrocar- 
diogram was continuously monitored on an oscillocscope. For recording of visual evoked cortical potentials (VECPs) from the primary visual cortex, two gold screw electrodes with a tip diameter of $1 \mathrm{~mm}$ were placed 3-4 $\mathrm{mm}$ lateral to the interhemispheric fissure and $1 \mathrm{~mm}$ frontal to the lambda fissure. Reference electrodes were placed $1 \mathrm{~mm}$ lateral to the midline and $1 \mathrm{~mm}$ before bregma. The electroretinogram (ERG) was recorded with chlorinated silver ball electrodes that were placed on each cornea in the lower temporal corner, and the electrode in the nontested eye, which was patched, was used as reference. Ocular movements were prevented by a suture through the conjunctivae. Visual stimuli were presented on a 17 -inch monitor (Acer View 76i) positioned $20 \mathrm{~cm}$ in front of the eye. The display was centered in a position $\sim 40^{\circ}$ medially from the pupil axis. It is known that the rat's eye is emmetropic and has large depth of focus because of the pinhole pupil (Chaudhuri et al., 1983). Light flashes of $20 \mu \mathrm{sec}$ duration were used at a rate of $1 \mathrm{~Hz}$, and bar stimulation consisted of vertical gratings of variable spatial frequency, alternating in phase with a temporal frequency of $1.8 \mathrm{~Hz}$ at $66 \%$ Michelson contrast (constant mean luminance, $15 \mathrm{~cd} / \mathrm{m}^{2}$ ). Signals were amplified 10,000-fold and bandpass filtered between 0.1 and $100 \mathrm{~Hz}$, and 128 events were averaged to improve the signal-to-noise ratio. Amplitudes of pattern ERG and pattern VECP were determined from the amplitude spectrum of a Fast-Fourier-transformation (DASYLab 3.0; Datalog GmbH \& Co. KG, Mönchengladbach, Germany) as the amplitudes of the second harmonic of the stimulation frequency. The noise level was considered to be the amplitude of the second harmonic in records with a covered stimulus and was determined for each eye in separate experiments. Visual acuity was assessed by plotting pattern ERG and pattern VECP amplitudes versus the spatial frequency and extrapolating the linear part of that curve (at least 3 data points) to the noise level. Mean amplitudes averaged from three separate measurements were used for analysis.

Quantification of $R G C$ density. At the end of each recording session, the rats received an overdose of chloral hydrate and were perfused via the aorta with $4 \%$ paraformaldehyde in PBS. The brain, the optic nerves, and both eyes were removed, and the retinas were dissected and flatmounted on glass slides. They were examined by fluorescence microscopy (Axiophot 2; Zeiss, Göttingen, Germany) using a UV filter (365/397 $\mathrm{nm})$, and RGC densities were determined by counting labeled cells in three areas $\left(62,500 \mu \mathrm{m}^{2}\right)$ per retinal quadrant at three different eccentricities of $1 / 6,3 / 6$, and $5 / 6$ of the retinal radius. Cell counts were performed by two independent investigators following a blind protocol.

Immunohistochemistry. Immunostaining was performed with cryostat sections (18 $\mu \mathrm{m}$ thick) of control and EAE retinas. DNA fragmentation of cells undergoing apoptosis was analyzed by the terminal deoxynucleotidyl transferase-mediated biotinylated UTP nick end labeling (TUNEL) method. Sections were incubated with $50 \mathrm{U}$ of terminal transferase and $1 \mathrm{~mm}$ biotin-dUTP in the presence of $1.5 \mathrm{mM} \mathrm{CoCl}_{2}, 0.2 \mathrm{M} \mathrm{K}^{+}$. cacodylate, and $25 \mathrm{mg} / \mathrm{ml} \mathrm{BSA}$ for $90 \mathrm{~min}$ at $37^{\circ} \mathrm{C}$. Incorporated biotinylated nucleotides were detected by incubation with fluorescein isothiocyanate-conjugated streptavidin and examined by fluorescence microscopy. Activated caspase-3 was determined using a rabbit polyclonal antibody (1:1000; PharMingen, San Diego, CA) and anti-rabbit IgG-cy3 (1:100) as second antibody. To examine resident and infiltrating cells in the retinas, the following antibodies were used: R-73 (1:200) specific for T-cell receptors of T-lymphocytes; and ED1 (1:200) that recognizes a lysosomal membrane-related antigen on macrophages-microglia. Sections were preincubated with $10 \%$ normal goat serum $[1 \mathrm{hr}$, room temperature (RT)], followed by primary antibodies (overnight,
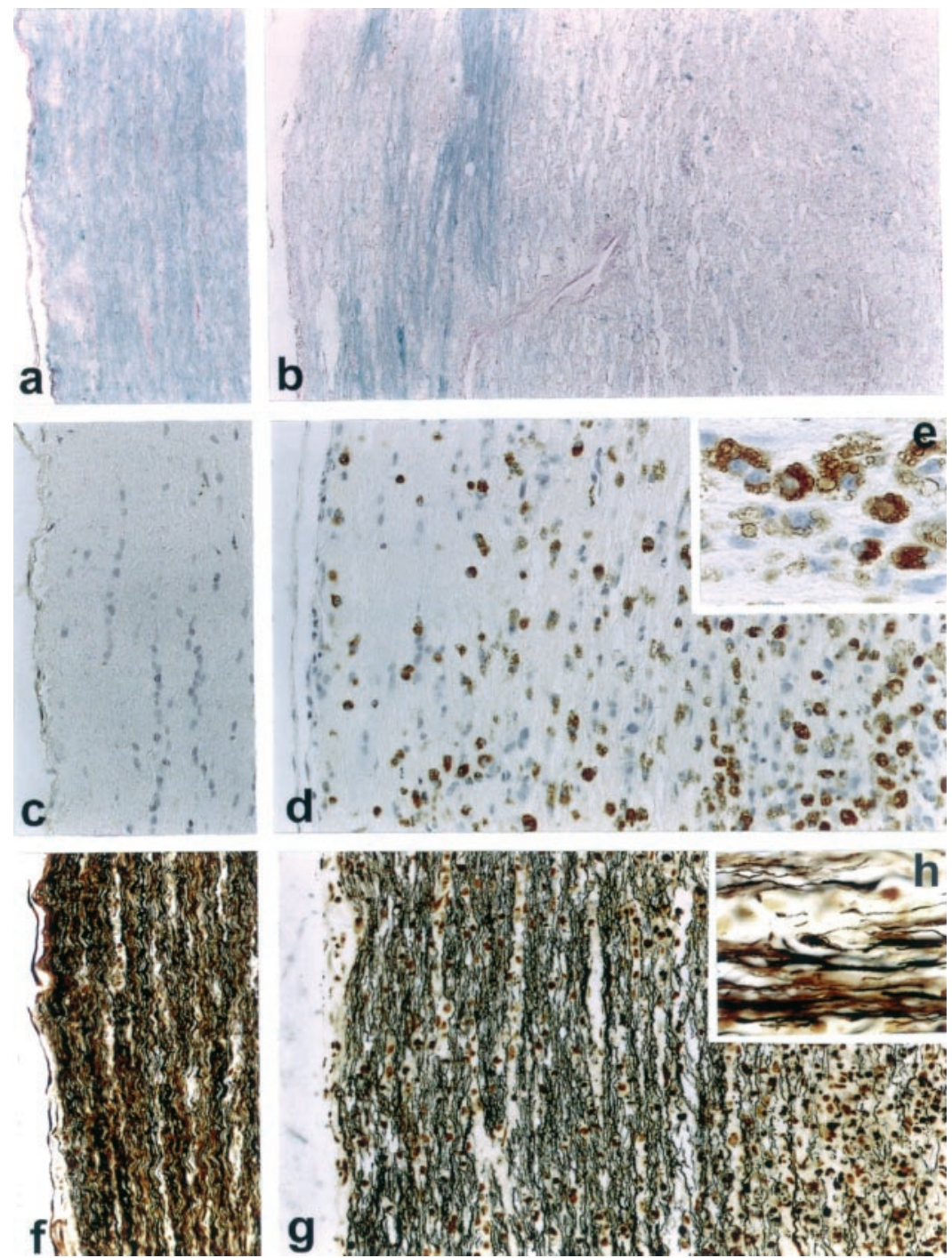

Figure 1. Lesional pathology in $\operatorname{EAE}(b, d, e, g, h)$ compared with healthy rats $(a, c, f)$. Serial longitudinal optic nerve sections were stained with Luxol fast blue $(a, b)$, ED1 (immunocytochemistry for activated macrophages and microglia; $c-e$ ), and Bielschowsky silver impregnation for axons $(f-h)$. On the left-hand side, the healthy optic nerve stained for Luxol fast blue (a), ED1 (c), and Bielschowsky silver impregnation $(f)$ is depicted. $b, d, e, g$, and $h$ show a mainly inactive demyelinated plaque with some ongoing demyelinating activity ( $b$, blue spots). At the edge of the plaque (left-hand side of $b, d, g$ ), some healthy Luxol fast blue-stained fibers remain unaffected $(b)$, whereas the center of the plaque is completely demyelinated $(b)$. The demyelinated area is heavily infiltrated by macrophages $(d, e)$. Bielschowsky silver impregnation $(g)$ reveals reduced density of apparently normal axons at the plaque edge. In the plaque center, density of axons is markedly reduced, and swollen and distorted axons $(h)$ can be detected. Magnification: $a-d, f, g, 300 \times ; e, h, 700 \times$. 
a

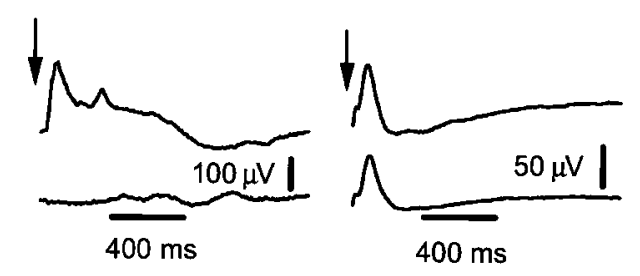

b

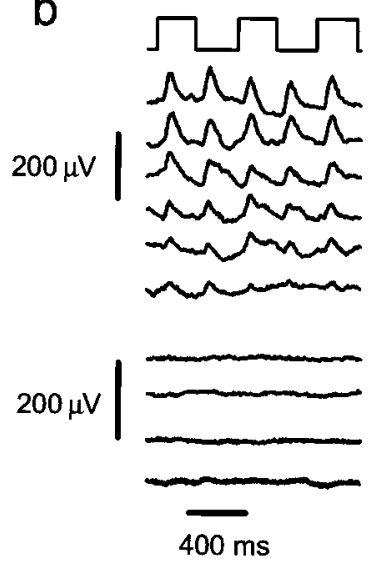

C

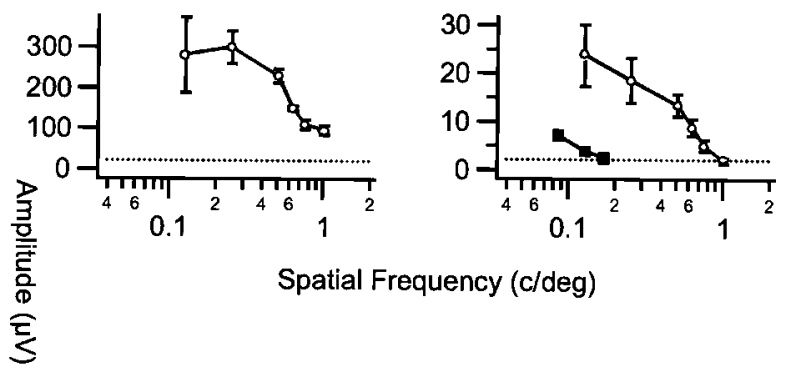

Figure 2. VECP and ERG responses in MOG-EAE and controls. $a$, VECP (left panel) and ERG (right panel) recordings in response to a flash-light indicated by arrows. The top traces represent a typical measurement from a control rat, and the bottom traces represent an rrMOG ${ }^{\text {Igd }}$ immunized BN rat with optic nerve demyelination. In diseased rats with MOG-EAE, no VECP signals could be recorded, but ERG was almost unchanged compared with control. $b$, Pattern VECP (left panel) and pattern ERG (right panel) traces recorded from a control $\mathrm{BN}$ rat (top traces) and from a BN rat with optic nerve demyelination (bottom traces) at varying spatial frequencies as marked by numbers are shown. The stimulating pattern is indicated on top of the recordings. Amplitudes of VECP and ERG decreased with increasing spatial frequencies. From the rat with optic neuritis, no VECP signals (left traces) in synchrony with the visual stimuli were obtained, and only ERG signals (right traces) with smaller amplitudes compared with controls could be detected. Traces at the bottom represent experiments with no visual stimulus to determine the noise level. $c$, Amplitudes of ERG and VECP recordings were plotted versus the spatial frequency. Open symbols mark data recorded from a control rat, and filled symbols mark data determined from a rat with optic neuritis. Visual acuities were evaluated by extrapolating amplitudes determined from VECP (right panel) and ERG (left panel) measurements to the noise level. Averaged data from three measurements with SEM are shown.

$4^{\circ} \mathrm{C}$ ) and $\mathrm{Cy}-3$ or fluorescein isothiocyanate-conjugated goat anti-mouse IgG serum (1 hr, RT; Dianova, Hamburg, Germany).

Histopathology. Histological evaluation was performed on paraformaldehyde-fixed, paraffin-embedded sections of brains and spinal cords. Paraffin sections were stained with hematoxylin-eosin, Luxol fast blue, and Bielschowsky silver impregnation to assess inflammation, demyelination, and axonal pathology, respectively, as described (Storch et al., 1998). In adjacent serial sections, immunohistochemistry was performed with ED1 antibody (Serotec, Oxford, UK) against macrophagesactivated microglia. Bound primary antibody was detected with a biotinavidin technique. Control sections were incubated in the absence of primary antibody (Storch et al., 1998). The investigators who processed tissue sections and diagnosed optic neuritis were blinded to the electrophysiological and immunohistochemical results of the study.

\section{RESULTS}

\section{Axonal transection in MOG-EAE}

We observed a widespread bilateral demyelination of the optic nerve in $41 \%$ ( 7 of 17 animals or 14 of 34 eyes) of the rrMOG ${ }^{\text {Igd }}$ immunized $\mathrm{BN}$ rats, which was assessed by a Luxol fast blue staining (Fig. 1b). Those rats with no signs of optic demyelination were also spared elsewhere in the CNS. In sections from control rats that were inoculated with CFA, a clear myelin staining of the optic nerve could be obtained (Fig. 1a). Demyelination of optic nerves was always connected with inflammation as shown by ED1-positive cells revealing activation of microglia or infiltration of macrophages, eosinophils, and neutrophils (Fig. 1d,e). In control rats, no ED1-positive cells were observed (Fig. 1c). Moreover, we observed axonal pathologies indicating axonal transection with the Bielschowsky's silver staining (Kornek et al., 2000). In demyelinated optic nerves, we found many swollen and distorted axons as well as axonal spheroids (Fig. $1 g, h)$ that were not seen in nerves from control rats (Fig. $1 f$ ).

\section{Loss of visual function in MOG-EAE}

The function of the optic system was investigated by VECPs and ERG recordings in response to flash and pattern stimuli (Fig. 2). Pattern experiments were performed to estimate visual acuities, and with flash experiments we tested whether axonal signaling was still intact. No flash-induced signal could be recorded with VECPs in rats with optic nerve inflammation and demyelination, whereas rats without affection of the optic nerve and controls showed VECPs similar to those recorded from control rats (Fig. $2 a$, left panel). ERGs recorded in response to flash stimuli are comparable for control and EAE rats with demyelinated axons, because these ERG recordings show the response of all electrically active cells in the retina with only a small impact by RGCs. However, pattern ERGs reflect the function of RGCs. In Figure $2 b$, pattern VECPs (left panel) and pattern ERGs (right panel) are shown. With increasing spatial frequencies, the amplitudes of VECP and ERG recordings decreased. The visual acuity was evaluated in each case by a linear extrapolation of the amplitude decrease to the noise level (Fig. $2 c$ ). We estimated visual acuities from control rats in the range of 0.7-1.4 cycles per degree, which is in accordance with reported visual acuities for pigmented rats of 1.18 cycles per degree (Silveira et al., 1987) to 0.9 cycles per degree (Beradi et al., 1990). From rrMOG $^{\text {Igd }}$ immunized rats without demyelination of the optic nerve, we recorded similar values. In contrast, ERG signals from rats with optic neuritis had smaller amplitudes, and visual acuities were significantly decreased to values below 0.5 cycles per degree. No VECPs could be recorded from these rats (Fig. $2 b, c$, Table 1). The numbers of included animals for each experimental group are shown in Table 1.

\section{Reduction of RGC density in MOG-EAE}

To examine the effect of rMOG $^{\text {Igd }}{ }_{\text {-induced EAE on the survival }}$ of RGCs, these cells were retrogradely labeled with FG, and cell density was determined after electrophysiological recordings had 
Table 1. Visual acuity and density of retinal ganglion cells of rats subjected to EAE or treated with CFA

\begin{tabular}{llllr} 
& \multicolumn{2}{l}{ Visual acuity (cycles per degree) } & & \multicolumn{2}{l}{$\begin{array}{l}\text { RGC density } \\
\left(\mathrm{mm}^{-2}\right)\end{array}$} & $n$ \\
\cline { 2 - 3 } & ERG & VECP & & $n$ \\
\hline Control (CFA) without optic neuritis & $1.10 \pm 0.13$ & $1.31 \pm 0.16$ & $2730 \pm 145$ & 9 \\
EAE (MOG) without optic neuritis & $0.99 \pm 0.04$ & $1.05 \pm 0.06$ & $2210 \pm 240$ & 20 \\
EAE (MOG) with optic neuritis & $0.33 \pm 0.07^{*}$ & - & $934 \pm 118^{*}$ & 14 \\
\hline
\end{tabular}

For presentation in Table 1, both eyes were considered separately. Optic neuritis was detected by evaluating demyelination (Luxol stain) and staining of macrophages-microglia (ED1). Data represent mean \pm SEM. Statistical significance was assessed using the Mann-Whitney $U$ test $\left({ }^{*} p<0.05\right)$.

been performed. In control retinas from CFA immunized rats, the mean RGC density was $2730 \pm 145$ FG-labeled cells per square millimeter, whereas in retinas from rats with a clear demyelination and axonal conduction block, the mean RGC density was reduced to $934 \pm 118$ cells per square millimeter (Fig. 3, Table 1). Cell densities were evaluated 14-30 d after immunization and 50-72 hr after the onset of clinical symptoms. Furthermore, in these retinas, we found additional staining of endothelial cells of retina vessels that could be distinguished by their fusiform shape and staining of microglia cells with variable morphology, ranging from rod-shaped to rather lumpy-shaped but usually showing marked ramification. The decrease of visual acuity obtained from pattern ERG measurements coincided with a significant reduction of RGC density. For the group of $\mathrm{rMOG}^{\mathrm{Igd}}$ immunized rats with no clear signs of optic neuritis, RGC densities showed broad variability ranging from values similar to that of controls to rather low values (Fig. $3 c$ ). Considering all data points in Figure $3 c$, it appears that functional disability occurs only beyond a threshold of RGC density.

\section{RGC cell death in MOG-EAE is apoptotic}

TUNEL staining of retinas with radial cryostat sections was performed to test for DNA degradation typical for apoptotic cell death. In rats with conduction block, TUNEL staining was positive in RGCs that were identified by FG staining (Fig. 4a,b). As a further proof of optic nerve inflammation-induced apoptosis in RGCs, activation of caspase-3 in RGCs was tested by immunohistochemical staining. In cryostat sections, activated caspase-3 was detected in FG-labeled RGCs (Fig. 4c,d). RGC death that was induced by an inflammatory cell infiltrate in the retinas was excluded, because neither infiltrating macrophages nor T-cells were ever detected in retinas by immunohistochemistry in this paradigm. As positive controls, sections from thymus were tested in parallel. Because of the lack of specific infiltrates in the retinas, the data indicate that axonal pathology was the cause of apoptotic RCG loss.

\section{DISCUSSION}

This study demonstrates that rrMOG $^{\text {Igd }}$-induced EAE in BN rats results in demyelination of the optic nerve and concomitant reduction of RGC density. Cell death of RGCs was apoptotic as shown by DNA degradation and activation of caspase-3 in RGCs. Therefore, we suggest that axonal damage induces acute secondary cell death in RGCs. This is supported by the fact that axotomy induces apoptosis of RGCs (Garcia-Valenzuela et al., 1994; Rabacchi et al., 1994; Isenmann et al., 1997). rMOG $^{\text {Igd_ }}$ induced EAE in rats results in axonal damage during active demyelination, and patterns of axonal pathology are qualitatively and quantitatively similar to those found in MS (Kornek et al., 2000). Recently, it has been suggested that in the course of EAE
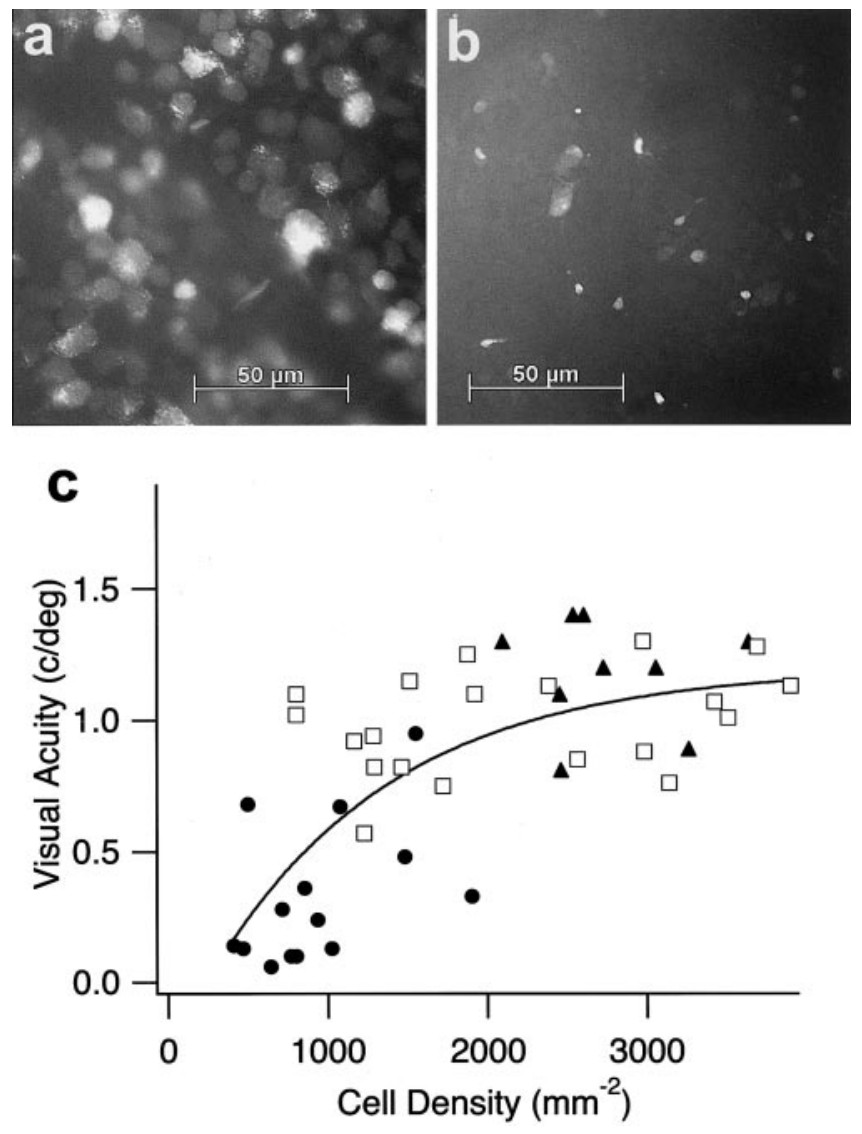

Figure 3. RGC density is reduced in $\mathrm{BN}$ rats with manifest optic neuritis. $a, b$, Representative whole-mount areas at $3 / 6$ retinal radius from a control rat $(a)$ and from an rMOG $^{\text {Igd }}$-immunized rat with optic neuritis (b) are shown. The numbers of FG-labeled RGCs are significantly reduced in $\mathrm{BN}$ rats with optic neuritis. $c$, The decrease of RGC density in rats with optic neuritis correlates with a reduction of visual acuity determined from ERG measurements. Visual acuities and RGC densities from rats with optic neuritis ( filled circles) are reduced compared with controls (filled triangle). $\mathrm{rrMOG}^{\mathrm{Igd}}$-immunized rats without optic neuritis (open squares) had similar visual acuities as controls, but RGC densities revealed a broader variability. The curved line marks the trend of all shown data points.

not only oligodendrocytes but also neurons are subjected to lymphocyte attack and may degenerate as shown for motoneurons of the spinal cord (Smith et al., 2000). In our study, demyelination of the optic nerve was connected with activation of microglia as well as infiltration of macrophages and eosinophils, which is in good agreement with the results of former work. Although CD4-positive T-cells have been shown to play a crucial role in the development of disease, a link has been demonstrated 

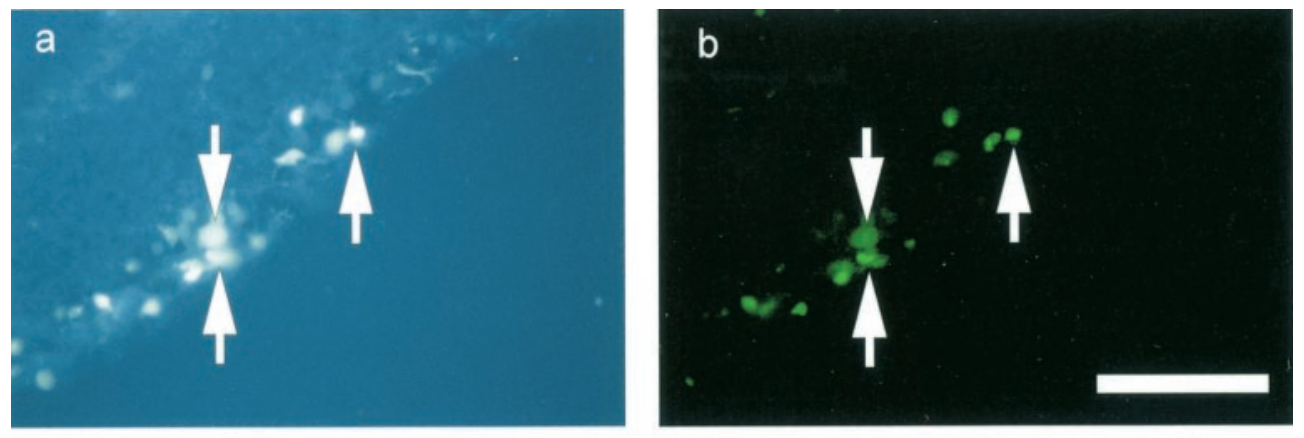

Figure 4. Cell death of RGCs is accompanied with DNA degradation and caspase activation indicating apoptotic neuronal death. $a, b$, Double staining of a representative retina section from a $\mathrm{BN}$ rat with optic neuritis. FG labeling $(a)$ colocalizes with TUNEL staining $(b)$, indicating apoptosis in RGCs. Large arrows mark identical cells. $c, d$, Detection of activated caspase-3 $(d)$ by immunohistochemistry in RGCs identified by FG labeling $(c)$. The small arrow marks an FGlabeled cell with no caspase-3 staining. Scale bars: $a, b, 100 \mu \mathrm{m} ; c, d, 70 \mu \mathrm{m}$.
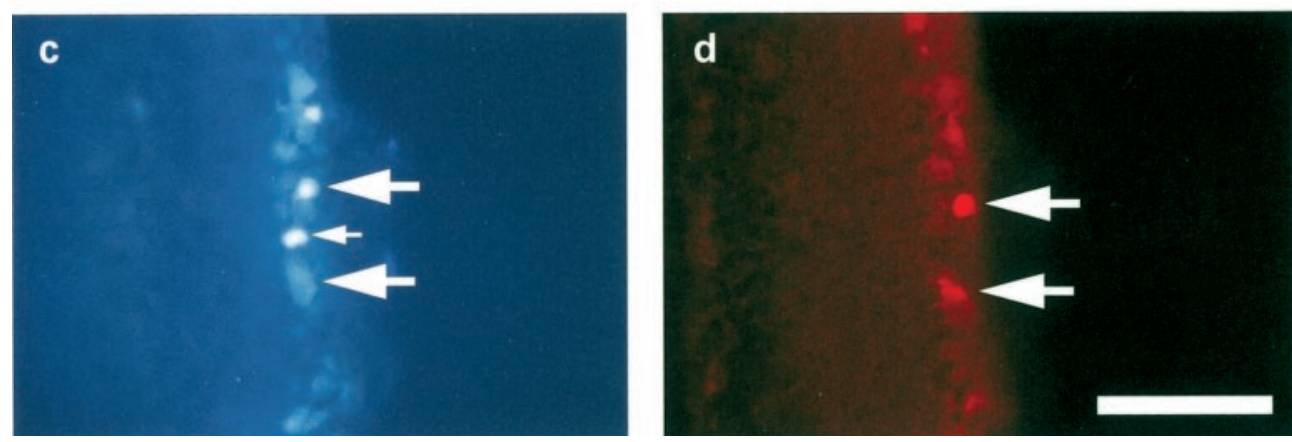

between eosinophil infiltration into the spinal cord of mice suffering from EAE and the development of paralysis (Gladue et al., 1996). In another study, infiltration of eosinophils into the optic nerves of mice after passive transfer of MBP-reactive T-cell blasts has been detected (Milici et al., 1998).

Neuronal apoptosis is important in development (Bähr, 2000). It is also present after nerve cell injury (Garcia-Valenzuela et al., 1994; Rabacchi et al., 1994; Isenmann et al., 1997). Furthermore, neuronal death in neurodegenerative diseases, such as Parkinson's disease and Alzheimer's disease, is thought to be apoptotic, although not formally proven (Selznick et al., 1999; Uetsuki et al., 1999; Jellinger et al., 2000). Even less evidence for neuronal apoptosis is currently available in MS and EAE. CSF from MS patients induces apoptotic cell death of neurons in cell culture (Alcazar et al., 1998), but apoptotic characteristics of neurons have not been detected in MS or EAE until now. The apoptotic signaling pathway involves upregulation of proapoptotic proteins such as c-Jun or Bax, release of cytochrome c, and finally activation of caspases (Bähr 2000). It can be transiently prevented by growth factors such as BDNF or insulin-like growth factor-1, as shown for cell death of RGCs induced by transection of the optic nerve (Klöcker et al., 1998; Kermer et al., 2000). The effector protein caspase-3, which leads to cell death by cleaving proteins, is involved in apoptosis of RGCs (Kermer et al., 1999). Moreover, inhibition of caspase-3 by protein inhibitors reduces in vivo apoptosis of RGCs after axotomy (Kermer et al., 1998).

In the present study, DNA degradation, a generally accepted feature of apoptosis, as well as activation of caspase- 3 could be detected in rat RGCs with an optic neuritis. Therefore, we suggest that cell death of RGCs in EAE is apoptotic. Because of the fact that cell death of RGCs is probably not synchronized, only a few RGCs per section were TUNEL-positive or showed activated caspase-3. Inflammatory retinal infiltrates consisting of T-cells or macrophages could not be detected in our experimental paradigm, which agrees with results of histopathologic studies in adult rhesus monkeys. These animals developed acute EAE together with optic neuritis and iridocyclitis but did not show inflammatory infiltration in the retina or around retinal vessels (Hayreh, 1981). Others demonstrated that anterior uveitis (AU) accompanies EAE as an ocular inflammatory manifestation and can be produced by T-cell immunity to myelin basic protein (MBP) (Verhagen et al., 1994; Adamus et al., 1996). In these studies, the kinetics of AU appears to differ from that of EAE. It has been shown that clinical symptoms of MBP-EAE peaked at days 13-14 after immunization, whereas inflammation of the anterior segment of the eye peaked during the state of EAE recovery. In our study, retinal tissue was examined in the first 50-72 hr after the onset of clinical symptoms related to EAE. Moreover, all cases of AU after EAE occurred after immunization with MPB. In animals with MOG-EAE, no cases of concomitant inflammation of ocular tissues have been reported.

A possible direct electrophysiological effect of MBP-specific encephalitogenic CD4 T-cells on axons has been shown using isolated optic nerve tissue. In this study, propagation of action potentials evoked by electrical stimulation was blocked by incubating optic nerves with specific anti-BP T-cells (Yarom et al., 1983). Others demonstrated that autoreactive T-cells in EAE may be neuroprotective. Autoimmune T-cells specific for myelin basic protein diminished the loss of RGCs after optic nerve crush because of a transient reduction in energy requirement caused by a decrease in nerve activity (Moalem et al., 1999). Using the mouse optic nerve crush model, it has also been shown that active immunization with encephalitogenic or nonencephalitogenic peptides of proteolipid protein or MOG can be beneficial in protecting RGCs from secondary cell death (Fisher et al., 2001). Cell death of spinal cord motoneurons induced by ventral root avulsion was reduced in rats suffering from EAE (Lovas et al., 2000). The mechanisms by which T-cells or active immunization increase survival of neurons is thought to be dependent on secretion of neurotrophins and other growth factors. The discrepancies in disease outcome between these studies and our data might be explained by the functional differentiation of T-cells infiltrating the CNS and activation of secondary immune cascades, like activation of B-cells secreting pathogenic antibodies (Stefferl et 
al., 1999), resulting either in protection or damage depending on a delicate balance between proapoptotic and antiapoptotic factors. The neuroprotective effect after immunization with immunodominant encephalitogenic epitopes could be achieved only when the disease they caused was mild (Fisher et al., 2001), supporting the idea of only a small gap existing between benign and destructive autoimmunity.

Nerve cell degeneration is generally supposed to be late and secondary in MS (Trapp et al., 1999; Lovas et al., 2000). This is questioned by the findings that axonal transection also occurred in patients with a short disease course (Ferguson et al., 1997; Trapp et al., 1999) and that the neuronal marker NMDA is reduced in early MS lesions and in normal appearing white matter (Davie et al., 1995). Furthermore, Trapp et al. (1998) showed that axonal ovoids, which are only transiently observed after nerve transection, are abundant in active MS lesions and that their frequency correlates with active inflammation. These findings raise the notion that axonal damage can begin early in the disease process and that axonal changes, demyelination, and tissue inflammation are closely associated events. Our study underscores a scenario in which axonal loss and neuronal degeneration are induced during active inflammation early in lesion development.

Published thresholds for spatial resolution of pigmented rats obtained from ERG (0.9 cycles per degree) (Berardi et al., 1990) or VECP measurements (1.2 cycles per degree) (Silveira et al., 1987) are similar to our values determined by ERG and VECP recordings (Table 1). Furthermore, in behavioral studies, a cutoff frequency of 1.2 cycles per degree was found (Birch et al., 1979). In regard to coincidence of RGC degeneration and alterations of ERG recordings, our results are in good agreement with results of others obtained in rats (Berardi et al., 1990), cats (Maffei et al., 1981, 1982; Hollander et al., 1984), and primates (Maffei et al., 1985). In those studies, degeneration of ganglion cells after optic nerve section leads to a reduction of the pattern ERG amplitude and leaves the flash ERG unaffected. Also visual acuity was reduced after axotomy of the optic nerve to values $<0.5$ cycles per degree (Domenici et al., 1991).

We did not observe a linear correlation for the visual disability and RGC density of rMOG $^{\text {Igd }}$-immunized rats (Fig. 3). Instead, it appears that visual function is not altered until RGC density reaches a certain threshold. By comparison, in the classic neurodegenerative diseases, amyotrophic lateral sclerosis and Parkinson's disease, it has been estimated that $50-80 \%$ of target neurons need to be lost before clinical onset of neurological disability (Lloyd et al., 1977; Bradley et al., 1987). This may be explained by the ability of mammalian CNS to compensate for the loss of neurons by plasticity and increased synaptogenesis (Kolb et al., 1989; Jones et al., 1994, 1996).

Our study revealed a strong correlation between inflammation and demyelination in MOG-EAE and a decrease of RGC density that is associated with a conductance block and a worsening of the visual acuity. RGC cell death was apoptotic. The factors that induce this apoptotic cell death after inflammatory attack of the optic nerve need to be defined. Moreover, we present a new model system that allows online monitoring of neuronal function during EAE. This model may be used to study the relations between the immune system, neuronal dysfunction, and cell death in more detail and to develop suitable combination treatment strategies. Importantly, the study gives the molecular rational for applying neuroprotective strategies in MS at an early time point and underscores the importance of early treatment in MS to prevent inflammation and associated neuronal death.

\section{REFERENCES}

Adamus G, Amundson D, Vainiene M, Ariail K, Machnicki M, Weinberg A, Offner H (1996) Myelin basic protein specific T-helper cells induce experimental anterior uveitis. J Neurosci Res 44:513-518.

Alcazar A, Regidor I, Masjuan J, Salinas M, Alvarez-Cermeno JC (1998) Induction of apoptosis by cerebrospinal fluid from patients with primary-progressive multiple sclerosis in cultured neurons. Neurosci Lett 255:75-78.

Bähr M (2000) Live or let die. Trends Neurosci 23:483-490.

Berardi N, Domenici L, Gravina A, Maffei L (1990) Pattern ERG in rats following section of the optic nerve. Exp Brain Res 79:539-546.

Birch D, Jacobs GH (1979) Spatial contrast sensitivity in albino and pigmented rats. Vision Res 19:933-937.

Bradley WG (1987) Recent views on amyotrophic lateral sclerosis with emphasis on electrophysiological studies. Muscle Nerve 10:490-502.

Brosnan CF, Raine CS (1996) Mechanisms of immune injury in multiple sclerosis. Brain Pathol 6:243-257.

Chaudhuri A, Hallett PE, Parker JA (1983) Aspheric curvatures, refractive indices and chromatic aberration for the rat eye. Vision Res 23:1351-1363.

Coles AJ, Wing MG, Molyneux P, Paolillo A, Davie CM, Hale G, Miller D, Waldmann H, Compston A (1999) Monoclonal antibody treatment exposes three mechanisms underlying the clinical course of multiple sclerosis. Ann Neurol 46:296-304.

Davie CA, Barker GJ, Webb S, Tofts PS, Thompson AJ, Harding AE, McDonald WI, Miller DH (1995) Persistent functional deficit in multiple sclerosis and autosomal dominant cerebellar ataxia is associated with axon loss. Brain 118:1583-1592.

Domenici L, Gravina A, Berardi N, Maffei L (1991) Different effects of intracranial and intraorbital section of the optic nerve on the functional responses of rat retinal ganglion cells. Exp Brain Res 86:579-584.

Ferguson B, Matyszak MK, Esiri MM, Perry VH (1997) Axonal damage in acute multiple sclerosis lesions. Brain 120:393-399.

Fisher J, Levkovitch-Verbin H, Schori H, Yoles E, Butovsky O, Kaye JF, Ben-Nun A, Shwartz M (2001) Vaccination for neuroprotection in the mouse optic nerve: implications for optic neuropathies. J Neurosci 21:136-142.

Garcia-Valenzuela E, Gorczyca W, Darzynkiewicz Z, Sharma SC (1994) Apoptosis in adult retinal ganglion cells after axotomy. J Neurobiol 25:431-438.

Gladue RP, Carroll LA, Milici AJ, Scampoli DN, Stukenbrok HA, Pettipher ER, Salter ED, Contillo L, Showell HJ (1996) Inhibition of leukotriene B4-receptor interaction suppresses eosinophil infiltration and disease pathology in a murine model of experimental allergic encephalomyelitis. J Exp Med 183:1893-1898.

Hayreh SS (1981) Experimental allergic encephalomyelitis. Retinal and other ocular manifestations. Invest Ophthalmol Vis Sci 21:270-281.

Hollander H, Bisti S, Maffei L, Hebel R (1984) Electroretinographic responses and retrograde changes of retinal morphology after intracranial optic nerve section. A quantitative analysis in the cat. Exp Brain Res 55:483-493.

Isenmann S, Wahl C, Krajewski S, Reed JC, Bähr M (1997) Upregulation of Bax protein in degenerating retinal ganglion cells precedes apoptotic cell death after optic nerve lesion in the rat. Eur J Neurosci 9:1763-1772.

Jellinger KA (2000) Cell death mechanisms in Parkinson's disease. J Neural Transm 107:1-29.

Jones TA, Schallert T (1994) Use-dependent growth of pyramidal neurons after neocortical damage. J Neurosci 14:2140-2152.

Jones TA, Kleim JA, Greenough WT (1996) Synaptogenesis and dendritic growth in the cortex opposite unilateral sensorimotor cortex damage in adult rats: a quantitative electron microscopic examination. Brain Res 733:142-148.

Kermer P, Klöcker N, Labes M, Bähr M (1998) Inhibition of CPP32-like proteases rescues axotomized retinal ganglion cells from secondary cell death in vivo. J Neurosci 18:4656-4662.

Kermer P, Klöcker N, Labes M, Thomsen S, Srinivasan A, Bähr M (1999) Activation of caspase-3 in axotomized rat retinal ganglion cells in vivo. FEBS Lett 453:361-364.

Kermer P, Klöcker N, Labes M, Bähr M (2000) Insulin-like growth factor-I protects axotomized rat retinal ganglion cells from secondary death via PI3-K-dependent Akt phosphorylation and inhibition of caspase-3 in vivo. J Neurosci 20:2-8.

Klöcker N, Cellerino A, Bähr M (1998) Free radical scavenging and inhibition of nitric oxide synthase potentiates the neurotrophic effects of brain-derived neurotrophic factor on axotomized retinal ganglion cells in vivo. J Neurosci 18:1038-1046.

Kolb B, Whishaw IQ (1989) Plasticity in the neocortex: mechanisms underlying recovery from early brain damage. Prog Neurobiol 32:235-276.

Kornek B, Storch MK, Weissert R, Wallstroem E, Stefferl A, Olsson T, Linington C, Schmidbauer M, Lassmann H (2000) Multiple sclerosis and chronic autoimmune encephalomyelitis: a comparative quantitative 
study of axonal injury in active, inactive, and remyelinated lesions. Am J Pathol 157:267-276.

Lassmann H (1998) Neuropathology in multiple sclerosis: new concepts. Mult Scler 4:93-98.

Lloyd KG (1977) CNS compensation to dopamine neuron loss in Parkinson's disease. Adv Exp Med Biol 90:255-266.

Lovas G, Szilagyi N, Majtenyi K, Palkovits M, Komoly S (2000) Axonal changes in chronic demyelinated cervical spinal cord plaques. Brain 123:308-317.

Maffei L, Fiorentini A (1981) Electroretinographic responses to alternating gratings before and after section of the optic nerve. Science 211:953-955.

Maffei L, Fiorentini A (1982) Electroretinographic responses to alternating gratings in the cat. Exp Brain Res 48:327-334.

Maffei L, Fiorentini A, Bisti S, Hollander H (1985) Pattern ERG in the monkey after section of the optic nerve. Exp Brain Res 59:423-425.

Milici AJ, Caroll LA, Stukenbrok HA, Shay AK, Gladue RP, Showell HJ (1998) Early eosinophil infiltration into the optic nerve of mice with experimental allergic encephalomyelitis. Lab Invest 78:1239-1244.

Moalem G, Leibowitz-Amit R, Yoles E, Mor F, Cohen IR, Schwartz M (1999) Autoimmune T cells protect neurons from secondary degeneration after central nervous system axotomy. Nat Med 5:49-55.

Noseworthy JH, Lucchinetti C, Rodriguez M, Weinshenker BG (2000) Multiple sclerosis. N Engl J Med 343:938-952.

Rabacchi SA, Bonfanti L, Liu XH, Maffei L (1994) Apoptotic cell death induced by optic nerve lesion in the neonatal rat. $J$ Neurosci 14:5292-5301.

Selznick LA, Holtzman DM, Han BH, Gokden M, Srinivasan AN, Johnson Jr EM, Roth KA (1999) In situ immunodetection of neuronal caspase-3 activation in Alzheimer disease. J Neuropathol Exp Neurol 58:1020-1026.

Silveira LC, Heywood CA, Cowey A (1987) Contrast sensitivity and visual acuity of the pigmented rat determined electrophysiologically. Vision Res 27:1719-1731.
Smith T, Groom A, Zhu B, Turski L (2000) Autoimmune encephalomyelitis ameliorated by AMPA antagonists. Nat Med 6:62-66.

Stefferl A, Brehm U, Storch M, Lambracht-Washington D, Bourquin C, Wonigeit K, Lassmann H, Linington C (1999) Myelin oligodendrocyte glycoprotein induces experimental autoimmune encephalomyelitis in the "resistant" Brown Norway rat: disease susceptibility is determined by MHC and MHC-linked effects on the B cell response. J Immunol 163:40-49.

Storch MK, Stefferl A, Brehm U, Weissert R, Wallstrom E, Kerschensteiner M, Olsson T, Linington C, Lassmann H (1998) Autoimmunity to myelin oligodendrocyte glycoprotein in rats mimics the spectrum of multiple sclerosis pathology. Brain Pathol 8:681-694.

Trapp BD, Peterson J, Ransohoff RM, Rudick R, Mork S, Bo L (1998) Axonal transection in the lesions of multiple sclerosis. N Engl J Med 338:278-285.

Trapp BD, Ransohoff R, Rudick R (1999) Axonal pathology in multiple sclerosis: relationship to neurologic disability. Curr Opin Neurol 12:295-302.

Uetsuki T, Takemoto K, Nishimura I, Okamoto M, Niinobe M, Momoi T, Miura M, Yoshikawa K (1999) Activation of neuronal caspase-3 by intracellular accumulation of wild-type Alzheimer amyloid precursor protein. J Neurosci 19:6955-6964.

Verhagen C, Mor F, Cohen IR (1994) T cell immunity to myelin basic protein induces anterior uveitis in Lewis rats. $\mathrm{J}$ Neuroimmunol 53:65-71.

Weissert R, Wallstrom E, Storch MK, Stefferl A, Lorentzen J, Lassmann H, Linington C, Olsson T (1998) MHC haplotype-dependent regulation of MOG-induced EAE in rats. J Clin Invest 102:1265-1273.

Wekerle H, Kojima K, Lannes-Vieira J, Lassmann H, Linington C (1994) Animal models. Ann Neurol [Suppl] 36:S47-S53.

Yarom Y, Naparstek Y, Lev-Ram V, Holoshitz J, Ben-Nun A, Cohen IR (1983) Immunospecific inhibition of nerve conduction by $\mathrm{T}$ lymphocytes reactive to basic protein of myelin. Nature 303:246-247. 